\title{
Retraction Note: Groundwater vulnerability based on bee colony optimization and real-time monitoring of exercise weight loss effect
}

\author{
Zou Lihua $^{1}$
}

Published online: 18 November 2021

C) Saudi Society for Geosciences 2021

Rectraction Note: Arabian Journal of Geosciences (2021) 14: 1550

https://doi.org/10.1007/s12517-021-08013-2

The Editor-in-Chief and the Publisher have retracted this article because the content of this article is nonsensical. The peer review process was not carried out in accordance with the Publisher's peer review policy. The author has not responded to correspondence regarding this retraction.

The original article can be found online at https://doi.org/10.1007/ s12517-021-08013-2.

\section{Zou Lihua}

lihuazou88@163.com

1 Sports Department of Jiangxi, University of Science and Technology, Nanchang City, Jiangxi Province, China 